\title{
SIMPLE ANSWERS TO USUAL QUESTIONS ABOUT UNUSUAL FORMS OF THE EVANS' ROOT LOCUS PLOT
}

\author{
L.H.A. Monteiro* \\ luizm@mackenzie.br, luizm@usp.br
}

\author{
J.J. Da Cruz ${ }^{\dagger}$ \\ jaimeelac.usp.br
}

*Escola de Engenharia da Universidade Presbiteriana Mackenzie e Escola Politécnica da Universidade de São Paulo

${ }^{\dagger}$ Escola Politécnica da Universidade de São Paulo

\begin{abstract}
After a first contact with Evans' root locus plots, in an introductory course about classical control theory, students usually pose questions for which the answers are not trivially found in the usual textbooks. Examples of such questions are: Can a branch intersect itself? Can two or more branches be coincident? Can a branch intersect its asymptote? In this paper devoted to helping teaching, numerical examples and an incremental property are used for answering some questions about unusual forms of root loci related to closed-loop control systems. In some cases, answering to these questions can be fundamental for making a correct sketch of a root locus.
\end{abstract}

KEYWORDS: feedback control, root locus method.

\section{RESUMO}

Após um primeiro contato com gráficos de Evans de lugar das raízes, num curso introdutório sobre teoria de controle clássico, os estudantes normalmente fazem perguntas para as quais as respostas não são encontradas trivialmente nos livros-textos usuais. Exemplos de tais questões são: Um ramo pode se auto-interseccionar? Dois ou mais ramos podem ser coincidentes? Um ramo pode interseccionar sua assíntota? Neste artigo com fins didáticos, usam-se exemplos

Artigo submetido em $31 / 01 / 2008$

1a. Revisão em 26/05/2008

2a. Revisão em 13/10/2008

Aceito sob recomendação do Editor Associado

Prof. José Roberto Castilho Piqueira numéricos e uma propriedade incremental para responder algumas questões sobre formas incomuns de lugar das raízes relacionadas a sistemas de controle em malha fechada. Em alguns casos, responder a essas questões pode ser fundamental para fazer um esboço correto de um lugar das raízes.

PALAVRAS-CHAVE: controle com realimentação, método do lugar das raízes.

\section{INTRODUCTION}

Analysis and design of linear time-invariant, singleinput/single-output, feedback control systems can be performed by using the root locus method. For instance, this method can be employed for determining the lock-in range of phase-locked loops (e.g. Piqueira and Monteiro, 2006). Root locus method was introduced in 1948 by W.R. Evans $(1948,1950)$ in order to make possible sketching the path (in the complex plane) of the closed-loop poles of control systems, as the value of a single parameter is varied. This parameter is normally the open-loop gain $k \geq 0$. If $G(s)$ is the open-loop transfer function, the closed-loop poles are the roots of the characteristic equation (e.g. Ogata, 2001):

$$
1+k G(s)=0
$$

By taking $G(s) \equiv b(s) / a(s)$, where $a(s)$ and $b(s)$ are real coprime polynomials of degrees $n$ and $m$, respectively, then (1) can be written as:

$$
1+k \frac{b(s)}{a(s)}=0
$$




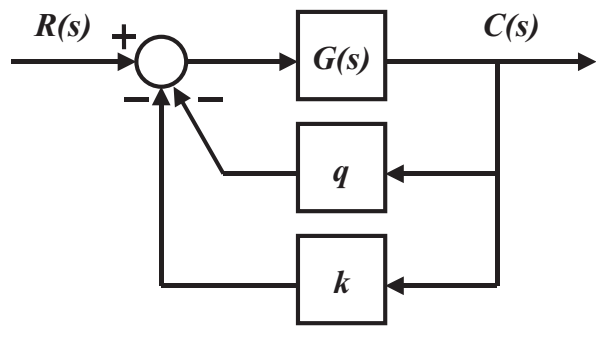

Figure 1: Block diagram of a control system.

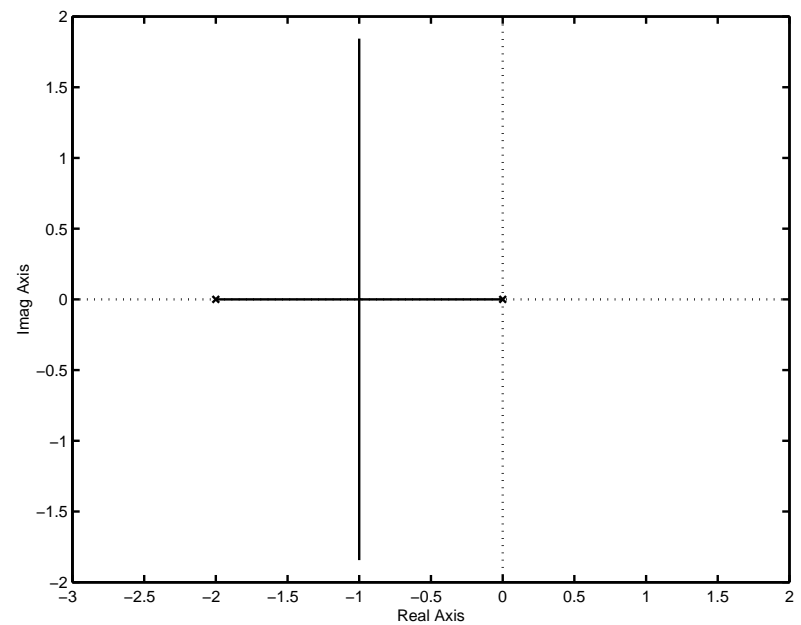

Figure 2: Root locus for $G(s)=1 /\left(s^{2}+2 s\right)$.

Evans derived rules that allow to sketch the loci (the branches) of the roots of equation (2) as $k$ is varied from zero to infinity, without solving such an equation (the case $k<0$ is studied, for instance, by Eydgahi and Ghavamzadeh, 2001; Teixeira et alii, 2004). This sketch is based on the values of the poles $p_{j}$ of $G(s)(j=1, \ldots, n)$, which are the $n$ roots of the polynomial $a(s)$; and on the zeros $z_{j}$ of $G(s)$ $(j=1, \ldots, m)$, which are the $m$ roots of the polynomial $b(s)$. For physically realizable systems, then $n \geq m$.

Evans' rules are usually presented in an introductory subject on control systems in undergraduate engineering courses and they are simple to be applied. Some well-known rules are (e.g. Kuo, 1967; Franklin et alii, 1986; Ogata, 2001): the number of branches of the root locus is equal to $n$; if $n>m$, then for $k \rightarrow \infty$ there are $v \equiv n-m$ branches approaching straight-line asymptotes; branches can leave from or arrive to the real axis, and so on.

However, after seeing some examples of root locus plot, students usually ask questions that can not be easily answered

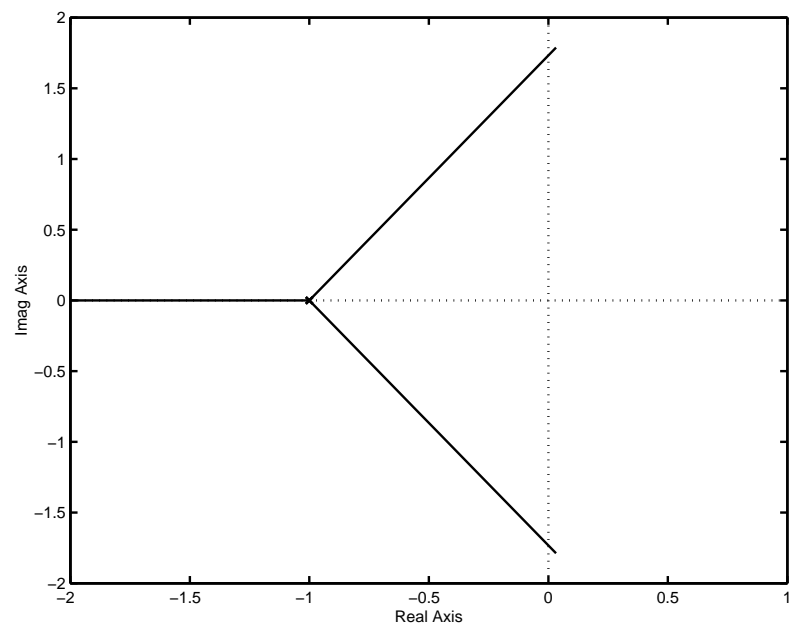

Figure 3: Root locus for $G(s)=1 /(s+1)^{3}$.

with the rules presented in the course and found in the textbooks. For instance: Which are the angles of departure (or arrival) of the branches leaving from (or arriving to) the real axis? Can a branch intersect itself? Can two or more branches have a common point? Can two or more branches be coincident for an open interval of values of $k$ ? Can a branch intersect its asymptote? Here, we answer such questions with numerical examples and/or arguments based on analytical expressions. These answers can be found in the literature (as cited below); however, they are barely used for sketching root loci. Here we present examples where the sketches of the corresponding root loci can not be appropriately made without such answers.

In the next section, an incremental property of the root locus plot is derived from a didactical block diagram. This property is employed in part of this study. The presented root loci were numerically plotted by using the software Matlab.

\section{INCREMENTAL PROPERTY}

Consider the feedback control system illustrated in Fig. 1 where $0 \leq q, k<\infty$. The closed-loop poles are given by:

$$
1+(q+k) G(s)=0
$$

or:

$$
1+k \frac{b(s)}{a(s)+q b(s)}=0
$$

When $q=0$, the root locus plot of this system is sketched by the usual rules, because the characteristic equations (2) and (4) become the same. Now, suppose that $q=q_{1}>0$. In this 


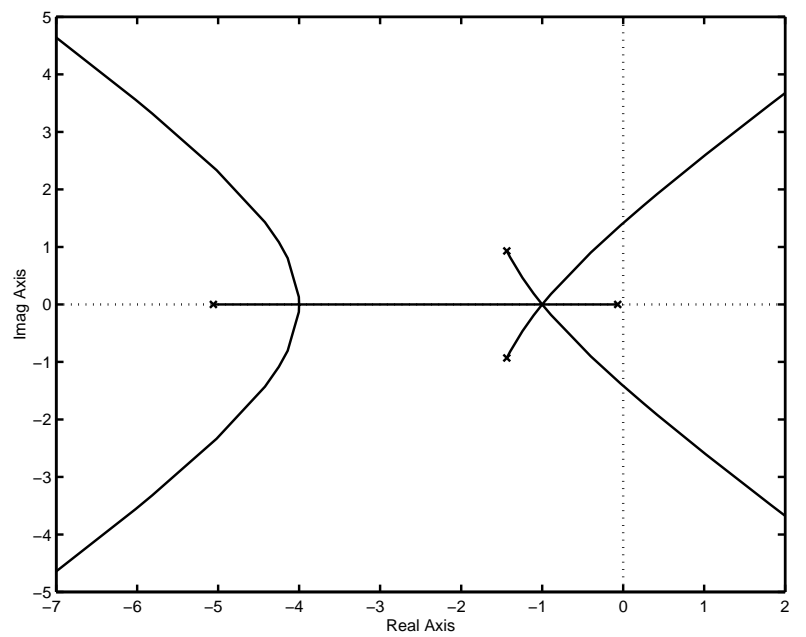

Figure 4: Root locus for $G(s)=1 /\left(s^{4}+8 s^{3}+18 s^{2}+16 s+\right.$ 1).

case, the root locus plot can be determined from the zeros of $G(s)$ (the roots of $b(s)$ ) and the closed-loop poles of $G(s)$ for $q=q_{1}$ (the roots of $a(s)+q_{1} b(s)$ ). This result represents an incremental property of the root locus plot: the closed-loop poles for $k>k_{1} \equiv q_{1}+k_{0}$ is a function of the open-loop zeros and of the closed-loop poles for $k=k_{1}$. The usual situation occurs for $k_{1}=0$, which implies that the roots of equation (2) depend on the roots of the polynomials $a(s)$ and $b(s)$, as Evans proved.

Incremental property, also denominated continuation property (e.g. Kuo, 1967; Pan and Chao, 1978; Franklin et alii, 1986; Paor, 2000), is an obvious consequence of the diagram shown in Fig. 1, which was not found in any control texts: the inner loop can be considered as the open-loop to draw the root locus for a varying $k>0$.

\section{ARRIVAL AND DEPARTURE ANGLES}

The angle associated to the complex number $s$ satisfying the equation (2) must be an odd multiple of $180^{\circ}$, because $k G(s)=-1$. Thus:

$$
\sum_{j=1}^{m} \phi_{j}-\sum_{j=1}^{n} \theta_{j}=(2 l+1) 180^{\circ}
$$

where $l=0, \pm 1, \pm 2, \ldots$. The angles of the vectors from the zeros $z_{j}$ and the poles $p_{j}$ to the number $s$ are, respectively, $\phi_{j} \equiv \arg \left(s-z_{j}\right)$ and $\theta_{j} \equiv \arg \left(s-p_{j}\right)$.

A breakaway point is a real root $s=s_{1}$ of equation (2) occurring at $k=k^{*}$ where $r$ branches (with $r \geq 2$ ) depart from

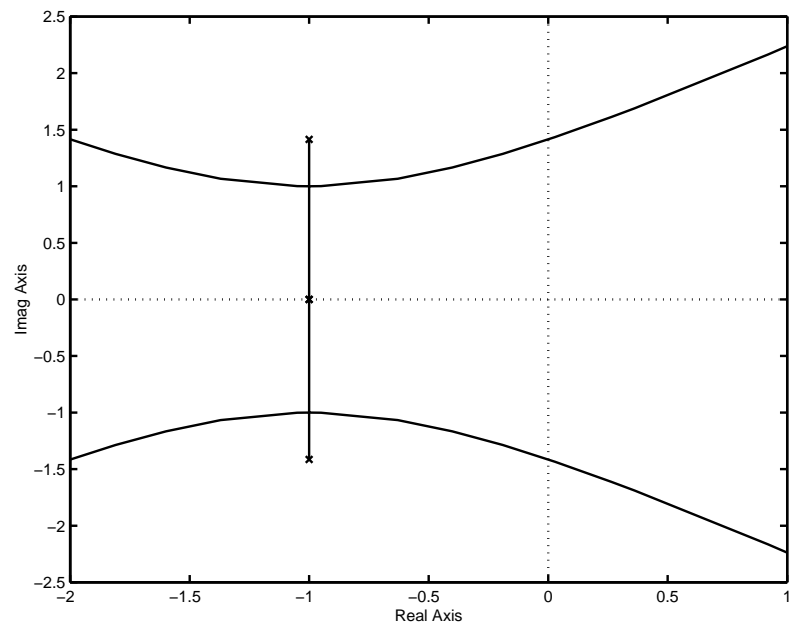

Figure 5: Root locus for $G(s)=1 /\left(s^{4}+4 s^{3}+8 s^{2}+8 s+3\right)$.

the real axis at $s=s_{1}$ for $k>k^{*}$. A break-in point is a real root $s=s_{1}$ of equation (2) occurring at $k=k^{*}$ where $r$ branches (with $r \geq 2$ ) arrive to the real axis at $s=s_{1}$ for $k>k^{*}$. In both cases, when $k=k^{*}$, then $s_{1}$ is a root of equation (2) with multiplicity $r$.

The incremental property can be used for obtaining angles of arrival and angles of departure from break-in and breakaway points, respectively. The usual example is given by $G(s)=$ $1 /\left(s^{2}+2 s\right)$, where the closed-loop poles are the roots of $s^{2}+2 s+k=0$. Notice that $s=s_{1}=-1$ is a root with multiplicity two for $k=k^{*}=1$; and for $k>1$, both roots become complex numbers. The departure angles from the real axis at $s=s_{1}$ can be determined from the closed loop poles at $k=k^{*}$. The expression (5) reveals that these angles are:

$$
\theta_{j}=\frac{180^{\circ}}{r}+j \frac{360^{\circ}}{r}
$$

with $j=0,1, \ldots, r-1$. In this case, $r=2$ and the departure angles are $90^{\circ}$ and $270^{\circ}$, as shown in Fig. 2.

For $G(s)=1 /(s+1)^{3}$, the departure angles are $60^{\circ}, 180^{\circ}$ and $300^{\circ}$, as illustrated in Fig. 3. These angles are obtained from expression (6) with $r=3$. Observe that $s=s_{1}=-1$ is the breakaway point at $k=k^{*}=0$, which is also the open-loop pole with multiplicity three.

For $G(s)=1 /\left(s^{4}+8 s^{3}+18 s^{2}+16 s+1\right)$, then $s=s_{1}=-1$ is a root with multiplicity three for $k=k^{*}=4$, as shown in Fig. 4. The departure angles obtained from (6) are the same of the previous example, which are $60^{\circ}, 180^{\circ}$ and $300^{\circ}$.

Similar plots were already presented by, for instance, Kuo 


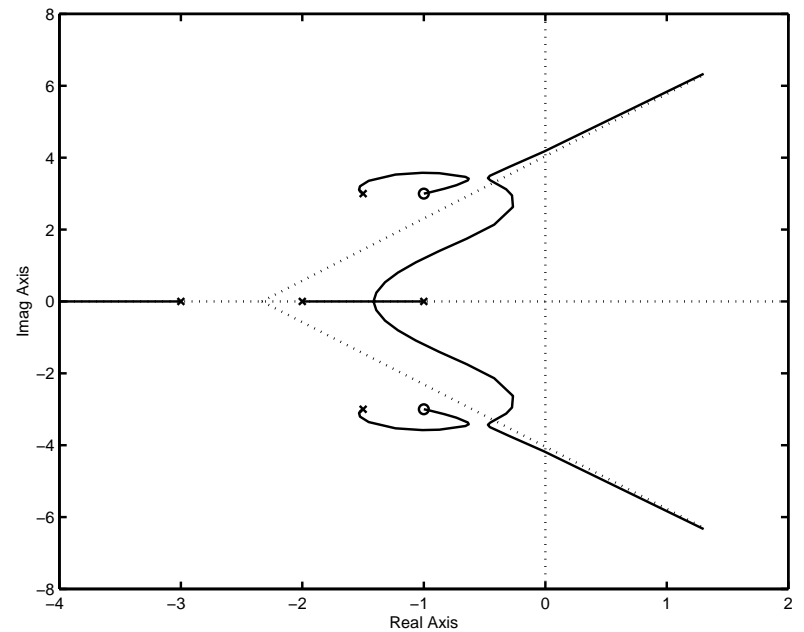

Figure 6: Root locus for $G(s)=\left(s^{2}+2 s+10\right) /\left(s^{5}+9 s^{4}+\right.$ $\left.40.25 s^{3}+106.5 s^{2}+141.75 s+67.5\right)$.

(1967) and Krajewski and Viaro (2007).

\section{INTERSECTION AMONG BRANCHES}

Breakaway and break-in points are usual examples of common points among branches on the real axis. However, there can be such points also out of the real axis.

- Two or more branches can intersect at a point that does not belong to the real axis.

Here intersection means having a common point (a different meaning is given by Lundberg (2007)). This situation occurs whenever there are multiple closed-loop poles outside the real axis. For instance, $G(s)=1 /\left(s^{4}+4 s^{3}+8 s^{2}+8 s+3\right)$ presents $s=-1 \pm i$ as closed-loop poles for $k=1$, both poles with multiplicity two. In this example, the departure angles from these complex poles are $0^{\circ}$ and $180^{\circ}$, as shown in Fig. 5 (found also in Kuo (1967)), because expression (6) reduces to:

$$
\theta_{j}=j .180^{\circ}
$$

with $j=0,1$.

\section{- A branch can not intersect itself.}

This property is immediate since, by construction, the gain $k$ increases along the root locus branches. By contradiction, if such an intersection occurred there would be a point corresponding to two distinct values of $k$.

- Two or more branches can not be coincident in an open interval of values of $k$.

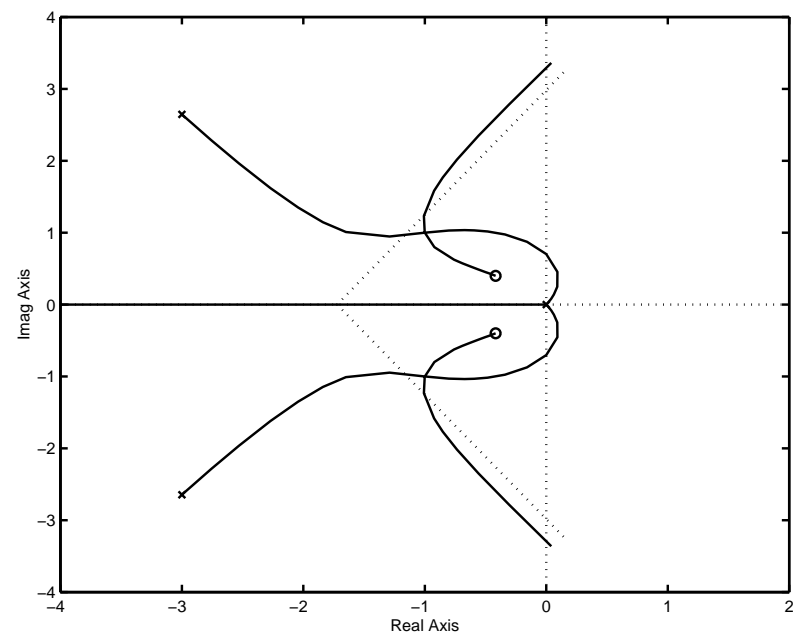

Figure 7: Root locus for $G(s)=\left(s^{2}+(5 / 6) s+\right.$ $(1 / 3)) /\left(s^{3}\left(s^{2}+6 s+16\right)\right)$.

This is because if branches intersect at a point of the complex plane for $k=k^{\prime}$, then they must separate following distinct angles for $k=k^{\prime}+q$, with $q \rightarrow 0_{+}$(these angles can be calculated by expression (6)). Consequently, these branches are no more coincident for $k=k^{\prime}+q$.

\section{INTERSECTION BETWEEN A BRANCH AND ITS ASYMPTOTE}

In Fig. 2, both branches for $k>1$ are coincident with the corresponding asymptotes. A similar behavior is observed in Fig. 3, where the three branches are coincident with their asymptotes for $k>0$. Thus, it is easy to find examples where a branch and its asymptote coincide for an open interval of values of $k$.

However, it is hard to build a transfer function where this coincidence happens at a unique point. In fact, such a behavior is possible and it is illustrated in Fig. 6, obtained for $G(s)=$ $\left(s^{2}+2 s+10\right) /\left(s^{5}+9 s^{4}+40.25 s^{3}+106.5 s^{2}+141.75 s+67.5\right)$ (other examples can be found in Kuo (1967) and Ogata (2001)). Notice that two branches present a common point with the corresponding straight-line asymptotes (represented in the figure by dotted lines forming angles of $60^{\circ}$ and $300^{\circ}$ with respect to the real axis). The third asymptote (at $180^{\circ}$ ) is coincident with its corresponding real branch for $k>0$.

\section{HARD TO SKETCH}

There are root loci hard of correctly sketching without investigating the existence of common points among branches out 


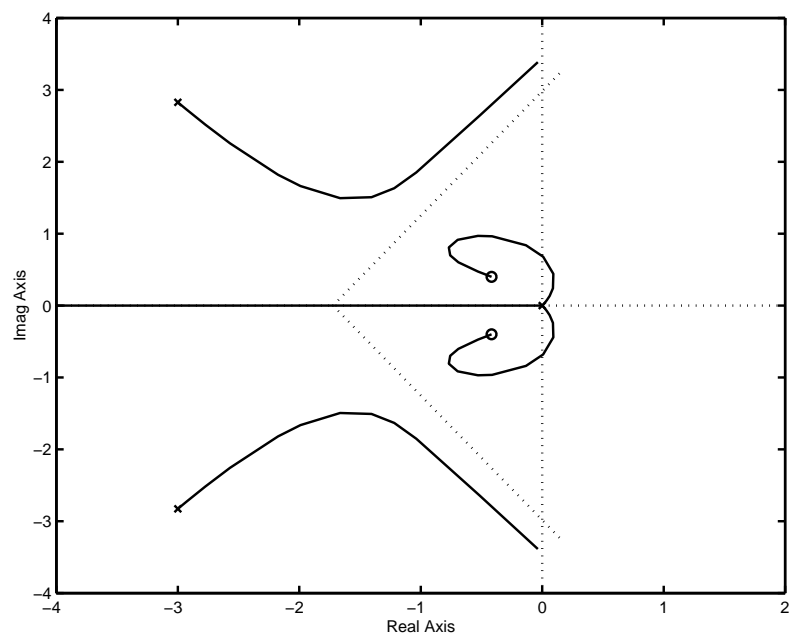

Figure 8: Root locus for $G(s)=\left(s^{2}+(5 / 6) s+\right.$ $(1 / 3)) /\left(s^{3}\left(s^{2}+6 s+17\right)\right)$.

the real axis and without determining the arrival and departure angles related to such points. In some cases, intersections among branches and asymptotes should also be investigated in order to perform a right sketch. For instance, take $G(s)=\left(s^{2}+(5 / 6) s+(1 / 3)\right) /\left(s^{3}\left(s^{2}+(6+\alpha) s+16+\beta\right)\right.$. Fig. 7 corresponds to $\alpha=0$ and $\beta=0$, Fig. 8 to $\alpha=0$ and $\beta=1$, and Fig. 9 to $\alpha=1$ and $\beta=0$. In all cases, the departure angles from the origin (a triple pole) are $60^{\circ}, 180^{\circ}$ and $300^{\circ}$, as in Fig. 4. In Fig. 7 there are two common points out of the real axis (in $-1 \pm i$ ); in the other cases such points do not exist. In Figs. 7 and 8 there are neither breakaway point nor break-in point and the branches going to infinity in the right half-plane arrive from the complex poles. However, in Fig. 7 two branches intersect twice their asymptotes; in Fig. 8 such intersections do not occur. In Fig. 9 there are one breakaway point and one break-in point, the branches going to infinity in the right half-plane come from the origin, and intersections among branches and asymptotes do not happen. Observe that correct sketches of the these cases can be made only if the common points among branches out the real axis and the intersections among branches and asymptotes are calculated. For instance, as in Fig. 8 there is no intersection among branches and asymptotes, then the branches going to infinity in the right half-plane must arrive from the complex poles and the ones going to zeros must arrive from the origin. In Fig. 9 as such intersections do not occur either, then the branches going to infinity in the right half-plane must come from the origin (because, if not, then two branches coming from the origin should intersect the asymptotes in order to arrive in the break-in point situated at the left of the point where the asymptotes meet the real axis).

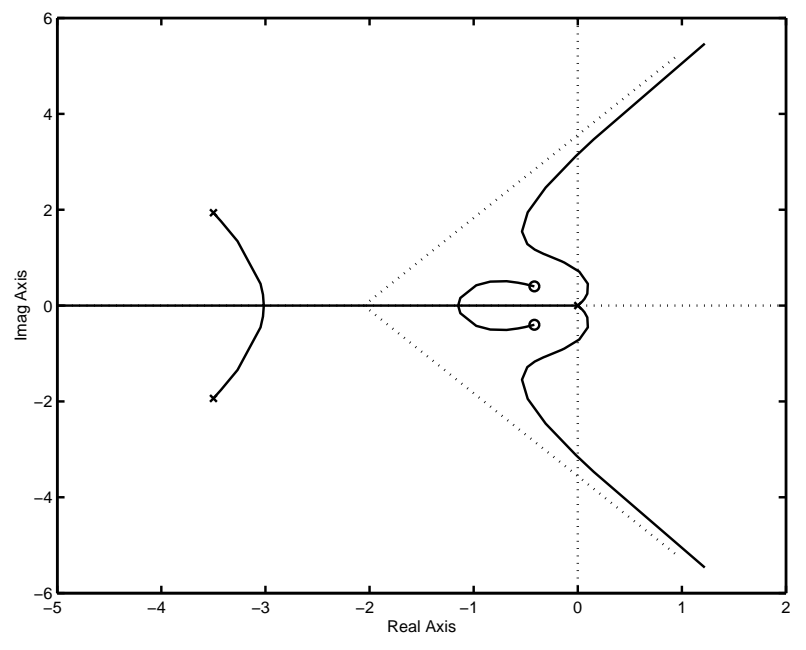

Figure 9: Root locus for $G(s)=\left(s^{2}+(5 / 6) s+\right.$ $(1 / 3)) /\left(s^{3}\left(s^{2}+7 s+16\right)\right)$.

By comparing the three last figures, it is evident that a root locus plot can be drastically changed by slightly varying $G(s)$ (in these cases, by slightly varying the positions of the openloop poles and keeping unaltered the positions of the zeros).

As a "homework" we suggest to sketch the case with $\alpha=0$ and $\beta=-1$.

\section{FINAL COMMENTS}

By using an incremental property (here didactically explained) and/or numerical examples, we answered the questions posed at the Introduction about unusual forms of root loci. The investigated features can be really useful for sketching root loci, as shown in the last section. We hope that the examples as well as the reasoning presented can help root locus teaching.

The authors are partially supported by CNPq.

\section{REFERENCES}

Evans, W.R. (1948). Analysis of Control System, AIEE Transactions, vol. 67, pp. 547-551.

Evans, W.R. (1950). Control System Synthesis and Root Locus Method, AIEE Transactions, vol. 69, pp. 66-69.

Eydgahi, A.M., Ghavamzadeh, M. (2001). Complementary Root Locus Revisited, IEEE Transactions on Education, vol. 44, pp. 137-143. 
Franklin, G.F., Powell, J.D., Emani-Naeini, A. (1986). Feedback Control of Dynamic Systems. Addison-Wesley, Reading, USA.

Krajewski, W., Viaro, U. (2007). Root-Locus Invariance Exploiting Alternative Arrival and Departure Points, IEEE Control Systems Magazine, vol. 27(1), pp. 36-43.

Kuo, B.C. (1967). Automatic Control Systems, Prentice-Hall, Englewood-Cliffs, USA.

Lundberg, K.H. (2007). Classical Crossroads, IEEE Control Systems Magazine, vol. 27(6), pp. 20-21.

Ogata, K. (2001). Modern Control Engineering, PrenticeHall, New York, USA.

Pan, C.T., Chao, K.S. (1978). A Computer-Aided Root Locus Method, IEEE Transactions on Automatic Control, vol. 23, pp. 856-860.

Paor, A.M. (2000). The Root Locus Method: Famous Curves, Control Designs and Non-control Applications, International Journal of Electrical Engineering Education, vol. 37, pp. 344-356.

Piqueira, J.R.C., Monteiro, L.H.A. (2006). All-Pole PhaseLocked Loops: Calculating Lock-In Range by Using Evan's Root-Locus, International Journal of Control, vol. 79, pp. 822-829.

Teixeira, M.C.M., Assunção, E., Machado, E.R.M.D. (2004). A Method for Plotting the Complementary Root Locus Using the Root-Locus (Positive Gain) Rules, IEEE Transactions on Education, vol. 47, pp. 405-409. 